Article

\title{
A Bio-Fluorometric Acetone Gas Imaging System for the Dynamic Analysis of Lipid Metabolism in Human Breath
}

\author{
Takahiro Arakawa $^{1}\left(\mathbb{D}\right.$, Naoki Mizukoshi $^{2}$, Kenta Iitani $^{1}\left(\mathbb{D}\right.$, Koji Toma $^{1}$ (D) and Kohji Mitsubayashi ${ }^{1, *(\mathbb{D})}$ \\ 1 Department of Biomedical Devices and Instrumentation, Institute of Biomaterials and Bioengineering, \\ Tokyo Medical and Dental University, 2-3-10 Kanda-Surugadai, Chiyoda-ku, Tokyo 101-0062, Japan; \\ arakawa.bdi@tmd.ac.jp (T.A.); i.bdi@tmd.ac.jp (K.I.); toma.bdi@tmd.ac.jp (K.T.) \\ 2 Graduate School of Medical and Dental Sciences, Tokyo Medical and Dental University, 1-5-45 Yushima, \\ Bunkyo-ku, Tokyo 113-8510, Japan; naokimizukoshi@icloud.com \\ * Correspondence: m.bdi@tmd.ac.jp
}

Citation: Arakawa, T.; Mizukoshi, N.; Iitani, K.; Toma, K.; Mitsubayashi, K. A Bio-Fluorometric Acetone Gas Imaging System for the Dynamic Analysis of Lipid Metabolism in Human Breath. Chemosensors 2021, 9, 258. https://doi.org/10.3390/ chemosensors 9090258

Academic Editor: Ji-Wook Yoon

Received: 31 July 2021

Accepted: 3 September 2021

Published: 9 September 2021

Publisher's Note: MDPI stays neutral with regard to jurisdictional claims in published maps and institutional affiliations.

Copyright: (c) 2021 by the authors. Licensee MDPI, Basel, Switzerland. This article is an open access article distributed under the terms and conditions of the Creative Commons Attribution (CC BY) license (https:// creativecommons.org/licenses/by/ $4.0 /)$.

\begin{abstract}
We constructed an imaging system to measure the concentration of acetone gas by acetone reduction using secondary alcohol dehydrogenase (S-ADH). Reduced nicotinamide adenine dinucleotide (NADH) was used as an electron donor, and acetone was imaged by fluorescence detection of the decrease in the autofluorescence of NADH. In this system, S-ADH-immobilized membranes wetted with buffer solution containing NADH were placed in a dark box, and UV-LED excitation sheets and a high-sensitivity camera were installed on both sides of the optical axis to enable loading of acetone gas. A hydrophilic polytetrafluoroethylene (H-PTFE) membrane with low autofluorescence was used as a substrate, and honeycomb-like through-hole structures were fabricated using a $\mathrm{CO}_{2}$ laser device. After loading the enzyme membrane with acetone gas standards, a decrease in fluorescence intensity was observed in accordance with the concentration of acetone gas. The degree of decrease in fluorescence intensity was calculated using image analysis software; it was possible to quantify acetone gas at concentrations of $50-2000 \mathrm{ppb}$, a range that includes the exhaled breath concentration of acetone in healthy subjects. We applied this imaging system to measure the acetone gas in the air exhaled by a healthy individual during fasting.
\end{abstract}

Keywords: imaging system; acetone; secondary alcohol dehydrogenase; enzyme; gas; UV-LED; lipid metabolism

\section{Introduction}

Human volatiles, such as exhaled breath and skin gas, contain hundreds of volatile organic compounds (VOCs), which can be collected noninvasively and easily [1-3]. Since the concentration of VOCs changes with diseases and metabolic abnormalities, measurement and analysis of VOCs in humans may assist in non-invasive evaluations of metabolism and disease screening [4-9].

It has been reported, for example, that the air exhaled by patients with diabetes contains higher concentrations of acetone gas than that exhaled by healthy individuals [8,10-12]. In addition, this concentration increases with fasting and exercise. The production of acetone gas by humans can be explained as follows. When the energy component of carbohydrates in the body is insufficient, fatty acids released from adipose tissue into the bloodstream are produced as ketone bodies (e.g., acetone, acetoacetate, and $\beta$-hydroxybutyrate) after undergoing $\beta$-oxidation $[10,13,14]$. Acetone, which is highly volatile, is carried through the body in the blood before being excreted as exhaled air or urine. By measuring the concentration of acetone, it is possible to evaluate lipid metabolism and the state of ketosis during exercise [15]. In addition, because of their insulin deficiency, patients with diabetes tend to be in the same metabolic state as people who are fasting, whereby fatty acids are preferentially used as an energy source. Therefore, measuring the 
concentration of acetone in exhaled air can be used to evaluate the lipid metabolism and detect diabetes in its early stages $[16,17]$.

Human breath and skin volatiles contain a mixture of more than 2000-3000 gaseous compounds [18-20]. The concentrations of these compounds can fluctuate considerably with time. The concentrations of the various gas components emanating from the human skin are very low (i.e., at a parts-per-billion (ppb) level) compared with those of the VOCs in breath and blood. Human skin volatiles are easier to collect than exhaled air since the measurements require less restriction. Therefore, skin gas sensors can be used to evaluate the biological condition of a subject without limiting their mobility. For instance, while the concentration of acetone in the exhaled air of healthy individuals at rest is $200-900 \mathrm{ppb}$, the concentration of acetone in skin gas is 77-97 ppb [21,22]. Similarly, the concentration of ethanol in the air exhaled by healthy individuals at rest is $37-207 \mathrm{ppb}$, while the ethanol concentration in the gas emitted from the skin is 3.6-79.2 ppb/min [23,24], even when measuring the upper arm or the whole hand. As the concentrations of ethanol and acetone released from the surface of the skin are extremely low, there is a demand for highly sensitive gas sensors and measurement techniques [25-29].

In recent years, progress in the production of analytical devices has enabled the measurement of minute amounts of odorous materials and volatile chemical components related to various diseases [30-32]. Body-derived gases (transdermal vapor), such as gases from halitosis and body odor, contain compounds produced by metabolic processes and ailment-specific components [33]. Representative VOCs in exhaled breath have been identified as possible diagnostic markers for various diseases. For example, acetone, ammonia, isoprene, 2-propanol, cyclohexanone, hydrogen sulfide, nitric oxide, ethane, carbon monoxide, acetaldehyde, and formaldehyde have been associated with disease [3,34-39]. High-sensitivity analysis or measurement of these volatile biological components are employed for medical diagnostics and disease screening.

Human volatiles are multicomponent mixtures, and their release kinetics and concentration distributions fluctuate over time. High gas selectivity, sensitivity, and responsiveness are important for measurements. Gas chromatography-mass spectrometry (GC-MS) and semiconductor sensors have already been utilized for the measurement of VOCs $[8,18,40]$. However, these methods have some limitations, such as complicated operation and gas selectivity, as well as an inability to accurately evaluate the spatio-temporal information of the gaseous compounds. Nevertheless, an enzyme-based gas sensor (biosniffer) can measure acetone in exhaled air with high sensitivity and selectivity [12,41]. Furthermore, by applying this technology, we were able to image ethanol and acetaldehyde in the exhaled breath and skin gas after drinking [42-44].

The aim of this study was to image and measure the acetone contained in human volatiles, which may be used for the evaluation of lipid metabolism. In this study, we constructed an acetone gas imaging system for exhaled gas measurement as preliminary research for future skin volatile measurement. After investigating the optimal conditions for the enzyme reaction, we constructed an acetone gas imaging system with selectivity and sensitivity and evaluated the characteristics of the sensor. In addition, this system was applied to the imaging of acetone gas in the exhaled breath by a healthy individual to investigate its usefulness in evaluating lipid metabolism.

\section{Materials and Methods}

\subsection{Construction of the Acetone Gas Imaging System}

In our system, acetone was reduced to isopropanol through a reaction catalyzed by secondary alcohol dehydrogenase (S-ADH) and producing oxidized NAD (NAD+); reduced nicotinamide adenine dinucleotide (NADH) was used as an electron donor. Equation (1) shows the principle of visualization and measurement of acetone gas based on the fluorescence of coenzyme NADH. NADH has auto-fluorescent properties (excitation: $340 \mathrm{~nm}$, fluorescence: $490 \mathrm{~nm}$ ). By combining an excitation light source and a high-sensitivity cam- 
era, we detected and visualized the NADH consumed in the enzymatic reaction following gas loading.

$$
\text { acetone }+\mathrm{NADH}+\mathrm{H}^{+} \stackrel{\mathrm{S}-\mathrm{ADH}}{\longrightarrow} 2-\text { propanol }+\mathrm{NAD}^{+}
$$

Imaging of the distribution of acetone gas was performed using a high-sensitivity complementary metal-oxide semiconductor (CMOS) camera to capture decreases in fluorescence intensity as a result of NADH consumption due to the reduction of acetone gas using S-ADH. Figure 1a-c shows the imaging system for acetone gas and direct breath gas supplying system. In this system, an ultraviolet-light-emitting diode (UV-LED) sheet $(340 \mathrm{~nm}, 9 \times 9$ LED array, $340 \times 081$ SFN; Dowa, Tokyo, Japan) and a CMOS camera $(\alpha 7 \mathrm{~S}$ II; Sony, Tokyo, Japan) were placed in a dark box facing each other across the immobilized $\mathrm{S}-\mathrm{ADH}$ mesh to provide uniform light irradiation to a two-dimensional surface. A bandpass filter $(\lambda=340 \pm 42.5 \mathrm{~nm}$; Edmond Optics, Barrington, NJ, USA) for excitation light was placed in front of the LED sheet, and a band-pass filter for fluorescence $(\lambda=490 \pm 10 \mathrm{~nm}$; Asahi Spectra, Tokyo, Japan) was placed in front of the camera lens.

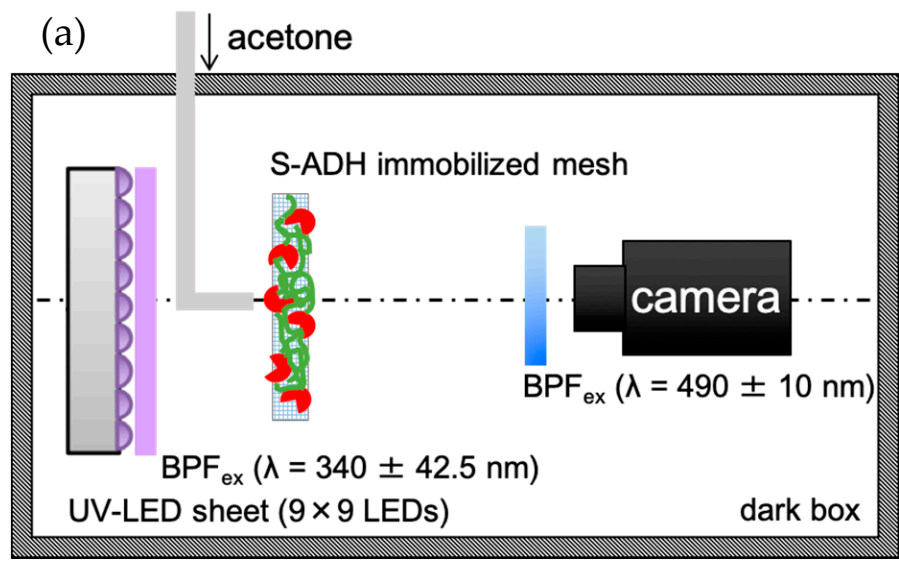

(c)

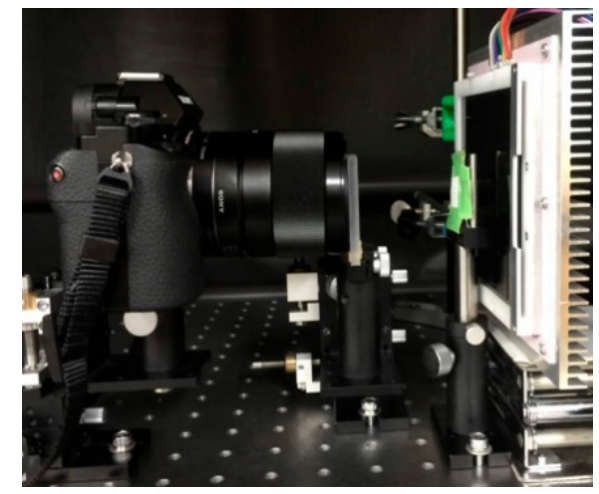

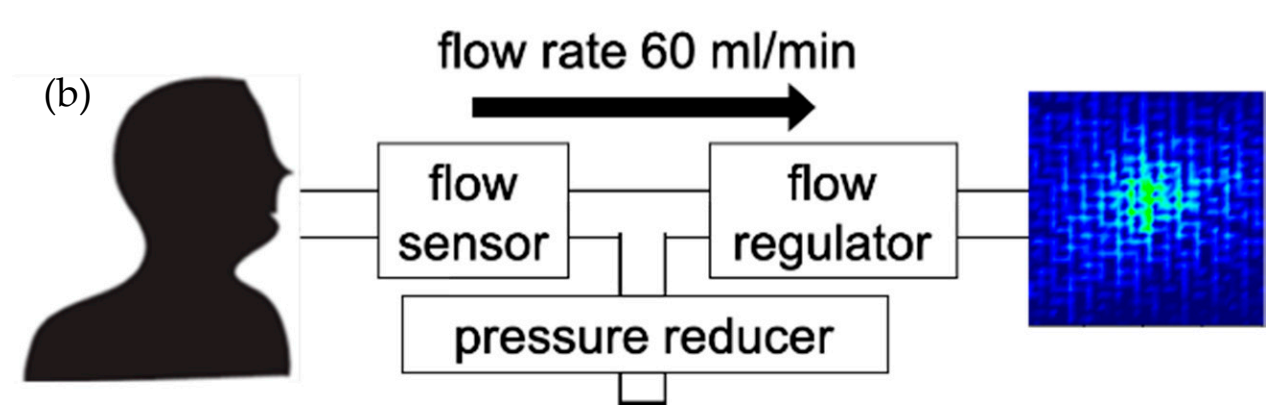

Figure 1. (a) Schematic illustration of the acetone gas imaging system using an UV-LED sheet, S-ADH immobilized mesh, and CMOS camera. (b) Schematic image of the direct breath gas imaging system using a flow sensor and flow regulator. (c) Photograph of the imaging system.

\subsection{Enzyme Immobilization Method}

For the visualization of acetone gas, we first prepared an S-ADH enzyme immobilization mesh that recognized acetone gas. The enzyme mesh was immobilized using enzyme immobilization materials. Since the autofluorescence of these materials interferes with imaging, we selected suitable materials and methods for immobilizing the enzyme with low autofluorescence. We chose cotton (Orange Care, Tokyo, Japan), hydrophilic polytetrafluoroethylene (H-PTFE; Merck Millipore Ltd., Burlington, MA, USA), and a cellulose dialysis membrane (UC-36-32-100; EIDIA Co., Ltd., Tokyo, Japan). Each substrate was cut into $20 \times 20 \mathrm{~mm}$ pieces, and autofluorescence was measured using an optical system for comparison. 
Next, we examined the materials used for immobilization of the enzyme. As immobilization materials, we evaluated copolymers of 2-methacryloyloxyethyl phosphorylcholine and 2-ethylhexyl methacrylate (PMEH) [45] and glutaraldehyde (GA; 25\% aqueous solution; Fujifilm Wako Chemical Co., Ltd., Tokyo, Japan). A cotton mesh substrate was loaded with 2.0 units of S-ADH (1 unit/mg; Daicel Corporation, Tokyo, Japan) immobilized using PMEH or GA. The S-ADH in the H-PTFE membrane was immobilized with PMEH. Each mesh substrate was soaked with an NADH solution in potassium phosphate buffer. The membranes with immobilized enzyme were placed in the imaging system to measure the decrease in fluorescence intensity with $1 \mathrm{ppm}$ acetone gas. For comparison, S-ADH was physically adsorbed onto a cotton mesh without using any immobilizing material.

Two types of mesh patterns, namely a square pattern and a honeycomb pattern (Figure S1), were prepared and fabricated by a $\mathrm{CO}_{2}$ laser cutting machine (ML-G 9300; KEYENCE). The laser intensity and scan speed were optimized, and the H-PTFE membrane was processed into a mesh. The H-PTFE mesh was cut into a $20 \times 20 \mathrm{~mm}^{2}$ piece and S-ADH was immobilized using PMEH. The pore size and thickness of the H-PTFE membrane (Merck Millipore Ltd., Burlington, MA, USA) were evaluated using a pore size of $10 \mu \mathrm{m}$ and a thickness of $85 \mu \mathrm{m}$.

\subsection{Characterization and Analysis Method of the Imaging System}

The amount of enzyme on the S-ADH-immobilized mesh was optimized. The enzyme meshes were produced by adding a mixture of S-ADH $(20 \mu \mathrm{L})$ and $10 \%$ PMEH $(20 \mu \mathrm{L})$ adjusted to each concentration $\left(0.1,0.25,0.5,1.0,1.5\right.$, and 2.0 units $\left./ \mathrm{cm}^{2}\right)$ onto the H-PTFE meshes processed into a honeycomb structure. The mixture was spread on the substrate and dried at $4{ }^{\circ} \mathrm{C}$ for $3 \mathrm{~h}$. Next, the enzyme mesh was soaked with $500 \mu \mathrm{M} \mathrm{NADH}$ solution $(40 \mu \mathrm{L})$ and placed in a dark box. Acetone gas $(1 \mathrm{ppm}, 60 \mathrm{~mL} / \mathrm{min})$ was loaded from the back side of the mesh, and the decrease in fluorescence induced by the enzyme reaction was captured by a high-sensitivity CMOS camera. Exposure time length was $33 \mathrm{~ms}$. We used image processing to quantify the effect of enzyme levels on output and responsiveness. The optimal $\mathrm{pH}$ for enzyme activity was also investigated. NADH solution $(500 \mu \mathrm{M})$ prepared in buffers of various $\mathrm{pH}$ (acetate: 3.0-5.0; potassium phosphate: 5.0-8.5; carbonate bicarbonate: 9.0-11.0) was added to the S-ADH solution. The NADH solution (500 mM; potassium phosphate: 5.0-8.5; carbonate bicarbonate: 9.0-11.0) was used to soak the immobilized S-ADH mesh and the output was compared after the loading of acetone gas standards. Subsequently, the fluorescence image was subjected to differential analysis using an image analysis software based on Equation (2) to improve the output response to acetone gas.

$$
\frac{\mathrm{dI}}{\mathrm{dt}}=\frac{\mathrm{g}(\mathrm{t}+\Delta \mathrm{t})-\mathrm{g}(\mathrm{t})}{\Delta \mathrm{t}}
$$

where I represents the intensity (a.u.), t represents the time (s), and g. (t):t (s) represents fluorescence intensity.

Next, various concentrations of acetone gas standards (50, 100, 200, 500, 1000, 1500, $2000 \mathrm{ppb}$ ) were loaded, and the fluorescence intensity and change in fluorescence due to the enzymatic reaction were determined to evaluate the quantitative characteristics of this system, such as selectivity. The fluorescence intensities were compared by loading the immobilized S-ADH mesh with an acetone gas standard prepared at $1 \mathrm{ppm}$ using representative components (i.e., acetone, 2-butanone, 2-pentanone, acetaldehyde, formaldehyde, methanol, 2-propanol, 1-propanol, ethanol, and 1-butanol).

\subsection{Imaging of Acetone Gas in Exhaled Air during Fasting}

The imaging system was used to measure acetone gas contained in exhaled air of individuals in a fasting state (Tokyo Medical and Dental University Ethics Committee Approval Number: M2018-160). After measuring body temperature, blood pressure, and pulse rate, as well as confirming the physical condition of the subjects, we assessed their diet and lifestyle using a questionnaire. For exhalation measurements, exhaled air was 
directly loaded into the imaging system using an exhalation flow control device every $1 \mathrm{~h}$ from $1 \mathrm{~h}$ before to $6 \mathrm{~h}$ after meals, and images were captured using a high-sensitivity camera. For the exhalation loading method, we first had the individual take a large breath in through the nose, hold it for $10 \mathrm{~s}$, and slowly exhale for $3 \mathrm{~s}$ to remove the exhalation air that had accumulated in the dead cavity. The exhaled air at each time point was collected in a Tedlar gas sampling bag ( $3 \mathrm{~L}$; AS ONE Co., Ltd., Osaka, Japan) and maintained in an incubation cover (I-cover; AS ONE) at $36^{\circ} \mathrm{C}$. The human subject was one healthy adult male. The concentration of acetone was measured through the solid phase microextraction method using GC-MS (JMS-Q1500GC; JEOL Co., Ltd., Tokyo, Japan).

\section{Results and Discussions}

\subsection{Evaluation of Enzyme Immobilization Methods and Substrates}

We investigated the autofluorescence of three types of substrates (H-PTFE, cotton, and cellulose membrane) for enzyme immobilization in the imaging system of acetone gas. In the comparison of fluorescence intensities, H-PTFE showed lower autofluorescence than cotton and cellulose membranes (Figure 2a). The autofluorescence of cotton and cellulose can be attributed to the high content of conjugated compounds, such as lignin, in naturally occurring fibers.

Next, S-ADH was immobilized on the H-PTFE membrane and cotton mesh by GA cross-linking or PMEH polymer, and changes in fluorescence upon loading of acetone gas standards were compared. The highest output was obtained following S-ADH immobilization on H-PTFE membranes with PMEH (Figure 2b). Therefore, H-PTFE was used as substrate for the comprehensive immobilization of S-ADH with PMEH. The GA immobilization method can exert a significant inhibitory effect on S-ADH.

In the enzymatic membranes using PMEH on the H-PTFE membrane, a decrease in NADH fluorescence induced by acetone gas loading was confirmed; however, variation in fluorescence distribution was observed. Therefore, we examined through-hole structures in the H-PTFE membrane to determine a way to reduce this variation.

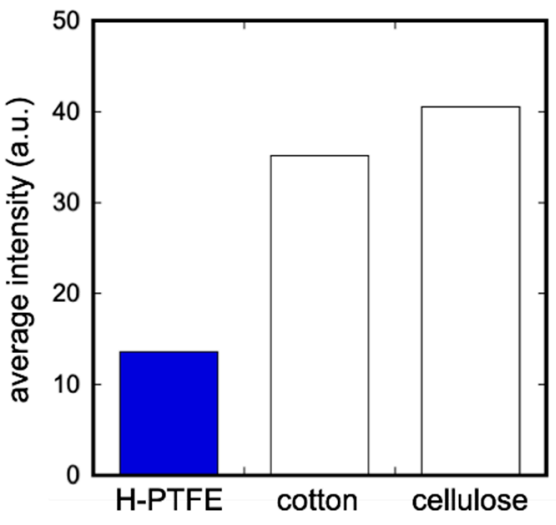

(a)

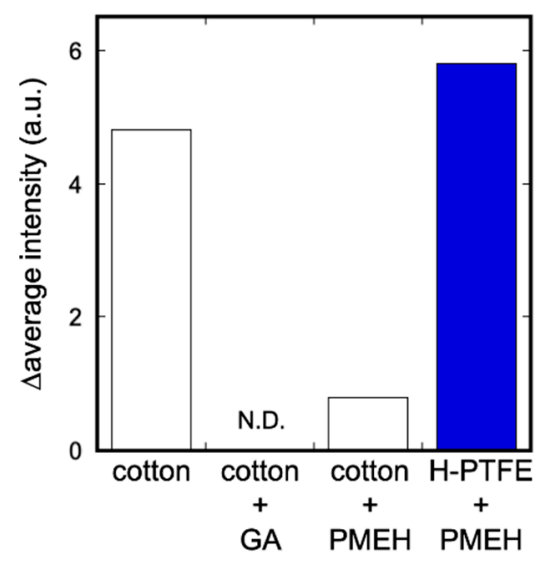

(b)

Figure 2. Evaluation and selection of enzyme immobilization substrates and immobilization materials. (a) Comparison of intrinsic fluorescence of the H-PTFE membrane, cotton mesh substrate, and cellulose membrane. (b) Comparison of the average intensity of combinations of substrates (cotton, $\mathrm{PMEH}$ ) and immobilization methods (glutaraldehyde, PMEH polymer) to $1.0 \mathrm{ppm}$ acetone gas. (a.u., arbitrary unit; GA, glutaraldehyde; H-PTFE, hydrophilic polytetrafluoroethylene; PMEH, 2-methacryloyloxyethyl phosphorylcholine and 2-ethylhexyl methacrylate). 
Imaging of acetone was carried out using H-PTFE meshes processed into square or honeycomb shapes (Figure 3). The variation in fluorescence distribution was reduced compared with that noted in cases without a through-hole structure. In particular, with the honeycomb shape, changes in fluorescence were observed around the gas loading point. Therefore, H-PTFE mesh processed into honeycomb shapes was used for the subsequent imaging of acetone gas.

The S-ADH mesh, an H-PTFE membrane immobilized with PMEH, has some shortcomings in fluorescence stability and drying during the acetone gas loading. We investigated the effect of pore size and thickness of H-PTFE membranes on the retention capacity of NADH solution and the drying of the membranes under gas loading. The results showed that the H-PTFE membranes with a pore size of $10 \mu \mathrm{m}$ and a thickness of $85 \mu \mathrm{m}$ produced by Millipore could be used for a relatively stable measurement of acetone gas.

\section{H-PTFE}
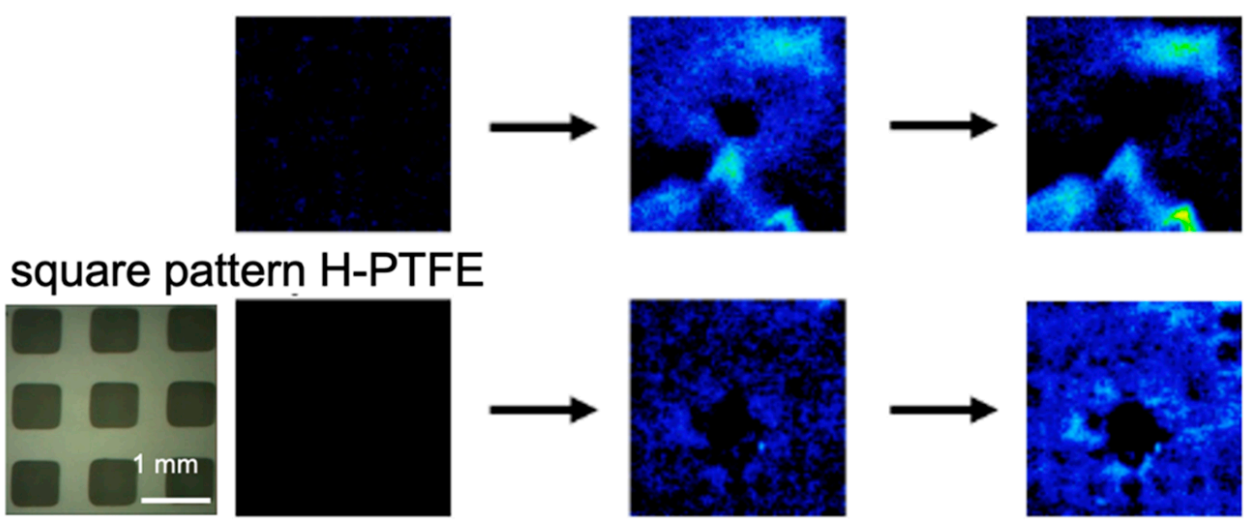

\section{honeycomb pattern H-PTFE}
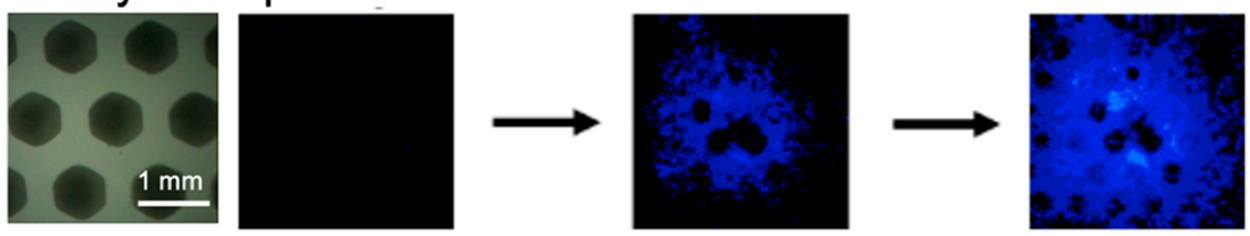

Figure 3. Change in fluorescence due to different pattern shapes (i.e., without pattern, square pattern, or honeycomb) of through-holes to suppress the accumulation of gas on the H-PTFE membrane. (left $0 \mathrm{~s}$, center $20 \mathrm{~s}$, right $120 \mathrm{~s}$ ).

\subsection{Characteristics of the Acetone Gas Imaging System}

The optimum $\mathrm{pH}$ of the imaging system was investigated. NADH solution $(500 \mu \mathrm{M}$, $40 \mu \mathrm{L}$ ) adjusted using various $\mathrm{pH}$ buffer solutions was applied to the immobilized S-ADH mesh, and the output response after loading of acetone gas (1.0 ppm) was compared. The maximum output was obtained with the $\mathrm{pH} 6.5$ potassium phosphate buffer solution. Enzyme meshes were fabricated with different amounts of enzyme $\left(0.25-2.0\right.$ units $\left./ \mathrm{cm}^{2}\right)$ and loaded with acetone gas standards. Based on these results, we decided to fabricate the enzyme-immobilized mesh using 0.5 units of S-ADH per $\mathrm{cm}^{2}$ and use an NADH solution adjusted to $\mathrm{pH} 6.5$ with potassium phosphate buffer solution for the subsequent measurements of acetone gas (Figure 4). We optimized the enzyme concentration. We examined the $90 \%$ output response time at $0.1-2.0$ units $/ \mathrm{cm}^{2}$ of enzyme volume. As shown in the Figure S2, the response time became shorter at 0.5 units. 


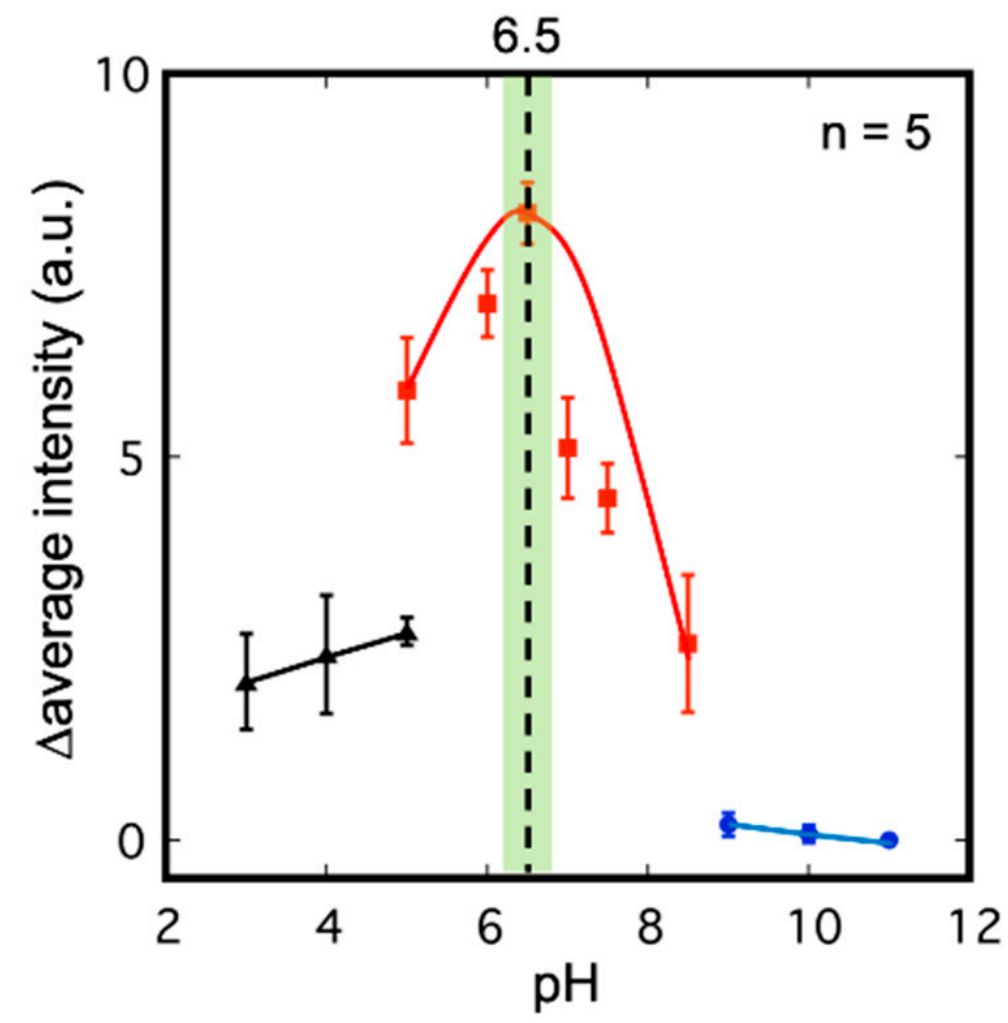

Figure 4. Evaluation of the $\mathrm{pH}$ dependence of fluorescence intensity in acetone gas imaging. ( (black): acetate 3.0, 4.0, 5.0; $\mathbf{\square}$ (red): potassium phosphate 5.0, 6.0, 6.5, 7.0, 7.5, 8.5; • (blue): carbonate bicarbonate 9.0, 10.0, 11.0).

Acetone gas standards were loaded on the enzyme mesh produced under the aforementioned conditions. A decrease in fluorescence around the loading point and a rapid stabilization of the fluorescence intensity after loading were observed. The fluorescence intensity was determined by analyzing the captured moving images, and the change over time is shown in Figure 5. However, since NADH is oxidized by acetone loading and NAD+ is generated and remains on the mesh, the change in distribution could not be evaluated. Therefore, differential analysis was used to determine the rate of change in fluorescence intensity per unit of time and display it as a moving image. Initially, we determined the $\Delta t$ value to evaluate the maximum value of the change rate in the differential analysis. By setting $\Delta \mathrm{t}$ to $2 \mathrm{~s}$ after the moving average, it was possible to calculate the differential value with a peak.

The lower image in Figure 5 shows the color image of the differentiated moving image at each time point $(0,20,120 \mathrm{~s})$. The peak curve obtained by the analysis shows an increase induced by gas loading and a decrease due to the cessation of gas loading; the spatio-temporal distribution could be expressed ( $90 \%: 37 \mathrm{~s}$ [fluorescence intensity] $\rightarrow$ $20 \mathrm{~s})$. The differential analysis of the fluorescence moving images obtained by the imaging system enabled us to capture information regarding the spatio-temporal distribution of acetone gas. 


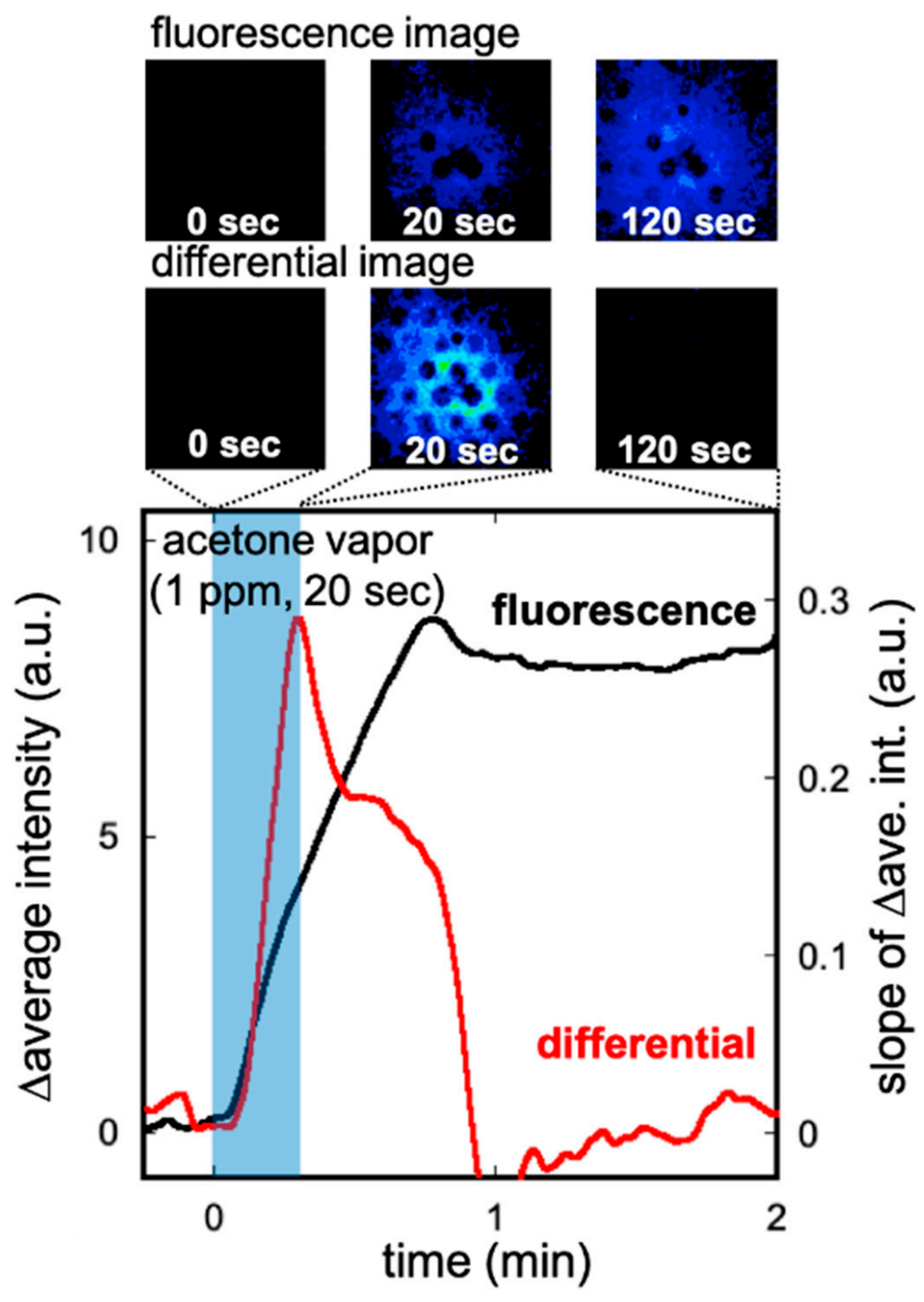

Figure 5. Change in fluorescence intensity over time in the imaging of acetone vapor (1.0 ppm), and results of the differential analysis after creating a running average based on the data. Inset images: fluorescence images (above) and differential analysis images (below).

The output power increased with gas loading. The fluorescence intensity (Figure 6a) and peak value (fluorescence variation) (Figure 6b) was observed at different concentrations. Based on the above results, the quantitative response to the concentration of acetone gas was evaluated from the steady-state value of fluorescence intensity and the peak value obtained from the differential analysis. It was possible to measure acetone gas at low concentrations using both fluorescence intensity and differential analysis. The quantitative Equations (3) and (4) $(R=0.999)$ used to determine the concentration of acetone in this system are as follows:

$$
\Delta \text { average intensity }=0.81+6.75[\text { acetone }(\mathrm{ppm})]
$$

$$
\text { Peak slope of } \Delta \text { average intensity }=0.072+0.14 \text { [acetone }(\mathrm{ppm})]
$$

The quantitative range obtained from each calibration equation was 0.05-2.00 ppm, which includes the acetone concentration (200-900 ppb) in the air exhaled by healthy individuals (Figure 6c). 

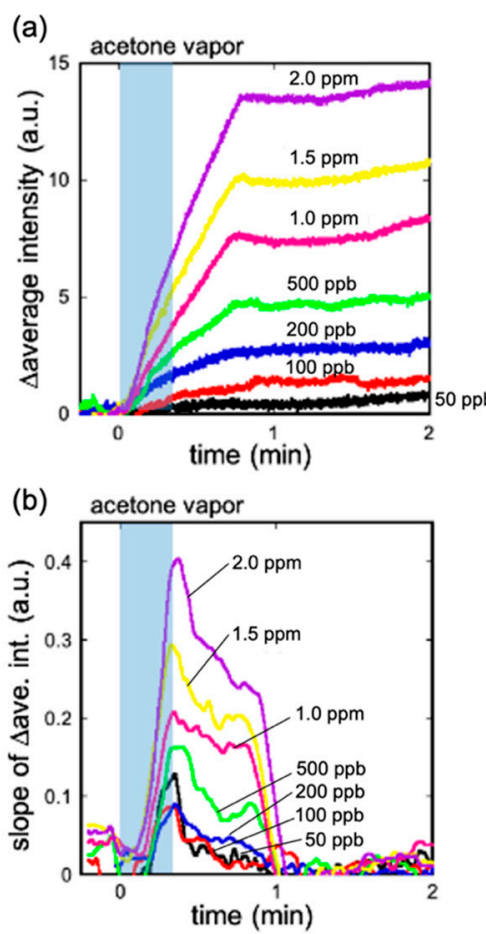

(c)

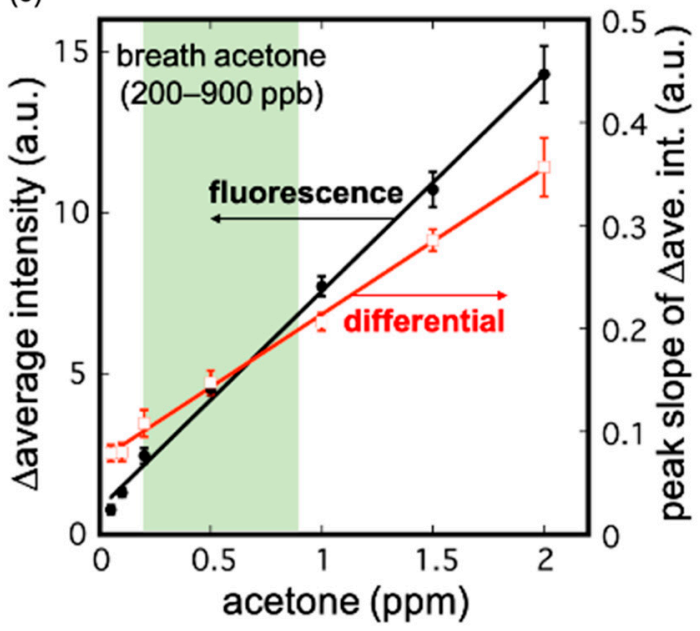

Figure 6. (a) Typical responses of the acetone vapor of 50 ppb, 100 ppb, 200 ppb, 1.0 ppm, 1.5 ppm, $2.0 \mathrm{ppm}$. (b) Differential analysis of each acetone concentration, which is calculated using a slope of the average fluorescence intensity. (c) Comparison of calibration formulae based on the results of fluorescence intensity $(\bullet)$ and differential analysis $(\square)$ against acetone vapor in the system.

We also evaluated the selectivity by loading representative components of exhaled air into the visualization system and comparing the outputs. Figure 7 shows the output for acetone gas as $100 \%$ and the output for other gases (at 1 ppm). The enzyme showed the highest output for acetone and high outputs for other ketones (2-butanone and 2pentanone). These results indicated gas selectivity based on the substrate specificity of the enzyme. Since the concentration of 2-butanone and 2-pentanone in exhaled air was lower than that of acetone (at 200-900 ppb), the effect on the measurement of acetone gas in vivo was minimal [46].

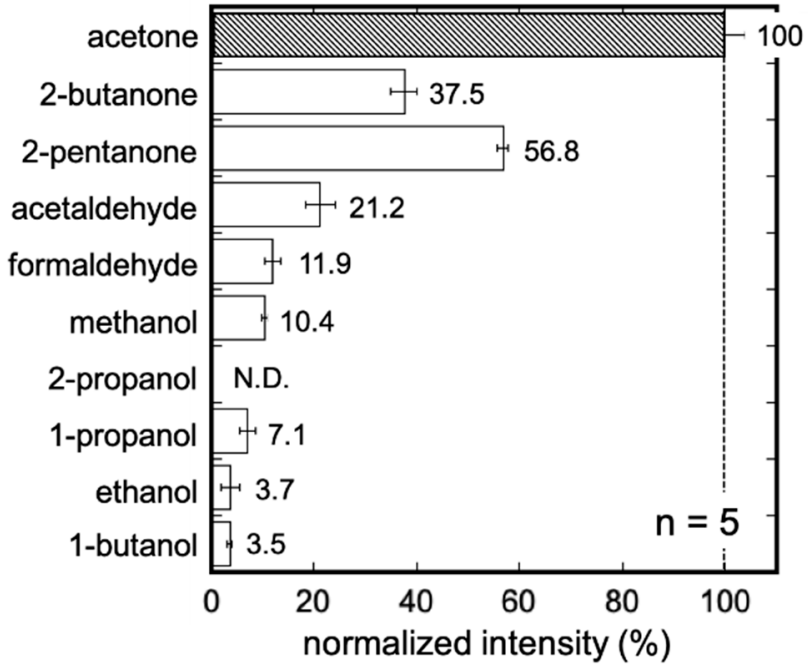

Figure 7. Gas selectivity of the acetone gas imaging system. The normalized intensity (\%) detected by the imaging system in response to 2-butanol (1 ppm) and 2-pentanone (1 ppm) was 37.5\% and $56.8 \%$, respectively. 


\subsection{Imaging of Breath Acetone Gas}

The imaging system for acetone was used for breath measurement while a human subject was in a fasting state. Following the loading of a sample of air exhaled by a healthy individual onto this system, a decrease in fluorescence derived from the acetone in the exhaled air was observed. We were able to calculate the concentration of acetone gas in the exhaled air based on the output values. Figure 8 and movie S1 shows the change in the concentration of acetone in exhaled breath over time due to meals.
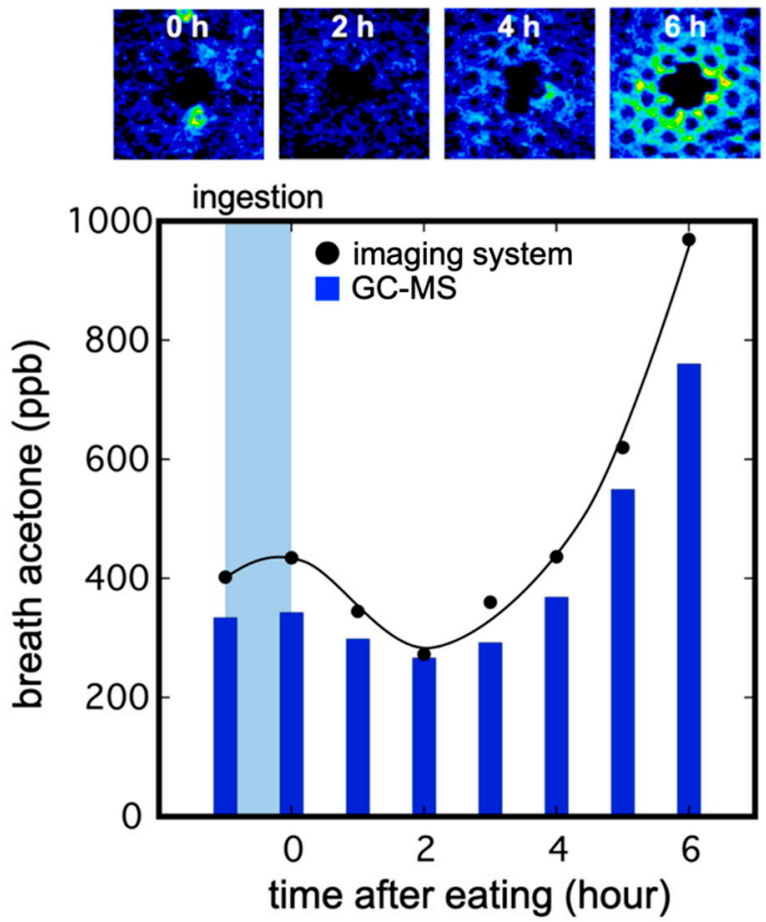

Figure 8. Change in the concentration of breath acetone gas over time, detected using an imaging system and gas chromatography-mass spectroscopy (GC-MS) before and after food intake. Upper images are max intensity image at each time after eating.

The concentrations of acetone before and immediately after the meal were identical. The concentration of acetone decreased with time, reaching its lowest value $2 \mathrm{~h}$ after the meal. Subsequently, it increased, reaching its highest value $6 \mathrm{~h}$ after the meal. This was attributed to the decrease in acetone concentration caused by the transition between lipid and glucose metabolism caused by the meal, as well as the increase in exhaled acetone concentration caused by lipid metabolism in the fasting state after the meal. For comparison, the concentration of acetone in the same exhaled air sample was measured using GC-MS. The somewhat low GC-MS value was attributed to the decrease in acetone concentration due to dissolution in the water condensed in the sample bag.

\section{Conclusions}

We developed an imaging and measurement system that can image acetone gas as an NADH fluorescent image using the reduction reaction of S-ADH. The system consists of an enzyme mesh with immobilized S-ADH, UV-LED sheets, and a high-sensitivity camera. It is capable of quantifying acetone gas in a concentration range from 0.05 to $2.00 \mathrm{ppm}$, a range that includes the concentration of acetone in the air exhaled by healthy individuals. The system was also able to display the spatio-temporal distribution of acetone gas by differential analysis of the obtained moving images. We applied this system to the air exhaled by a healthy individual, and were able to visualize and measure the exhaled acetone gas. The concentration of acetone gas increased and decreased, with the minimum value observed $2 \mathrm{~h}$ after a meal. This finding suggests that this system can be 
used to evaluate lipid metabolism. In the future, the imaging of volatile components of diverse biological origins may be applied to disease screening and the exploration of sites generating human volatiles.

Supplementary Materials: The following are available online at https:/ / www.mdpi.com/article/10 .3390 / chemosensors $9090258 /$ s1, Figure S1: Designs of a square pattern and a honeycomb pattern were prepared and fabricated on a $\mathrm{CO}_{2}$ laser cutting machine. Figure S2: Comparison of fluorescence intensity (red plots) and 90\% output response time (black plots) versus enzyme amount for imaging system. Movie S1: Video of changes in the concentration of acetone in exhaled breath.

Author Contributions: Conceptualization, T.A., K.I., K.T. and K.M.; methodology, T.A., N.M., K.I., K.T. and K.M.; software, N.M. and K.I.; validation, T.A., N.M. and K.M.; formal analysis, N.M. and K.I.; investigation, T.A., N.M., K.I., K.T. and K.M.; resources, T.A. and N.M.; data curation, T.A. and N.M.; writing — original draft preparation, T.A.; writing—review and editing, T.A. and K.M.; visualization, T.A., N.M. and K.I.; supervision, K.M.; project administration, T.A. and K.M.; funding acquisition, T.A. and K.M. All authors have read and agreed to the published version of the manuscript.

Funding: This work was supported by the JSPS KAKENHI grant numbers JP19J01649, JP17H01759, JP16J09604, and JP15H04013; and the Ministry of Education, Culture, Sports, Science and Technology (MEXT) Special Funds for "Cooperative Research Project of Research Center for Biomedical Engineering".

Institutional Review Board Statement: The study was conducted according to the guidelines of the Declaration of Helsinki, and approved by the Ethics Committee of Institute of Biomaterials and Bioengineering, Tokyo Medical and Dental University (approval number: M2018-160).

Informed Consent Statement: Informed consent was obtained from all subjects involved in the study.

Conflicts of Interest: The authors declare no conflict of interest.

\section{References}

1. Dormont, L.; Bessière, J.M.; Cohuet, A. Human Skin Volatiles: A Review. J. Chem. Ecol. 2013, 39, 569-578. [CrossRef]

2. Dormont, L.; Bessiere, J.-M.; McKey, D.; Cohuet, A. New Methods for Field Collection of Human Skin Volatiles and Perspectives for Their Application in the Chemical Ecology of Human-Pathogen-Vector Interactions. J. Exp. Biol. 2013, 216, $2783-2788$. [CrossRef]

3. de Lacy Costello, B.; Amann, A.; Al-Kateb, H.; Flynn, C.; Filipiak, W.; Khalid, T.; Osborne, D.; Ratcliffe, N.M. A Review of the Volatiles from the Healthy Human Body. J. Breath Res. 2014, 8, 014001. [CrossRef]

4. Lourenço, C.; Turner, C. Breath Analysis in Disease Diagnosis: Methodological Considerations and Applications. Metabolites 2014, 4, 465-498. [CrossRef]

5. $\quad$ Longo, N.; Li, S.K.; Yan, G.; Kochambilli, R.P.; Papangkorn, K.; Berglund, D.; Ghanem, A.H.; Ashurst, C.L.; Ernst, S.L.; Pasquali, M.; et al. Noninvasive Measurement of Phenylalanine by Iontophoretic Extraction in Patients with Phenylketonuria. J. Inherit. Metab. Dis. 2007, 30, 910-915. [CrossRef]

6. $\quad$ Rattray, N.J.W.; Hamrang, Z.; Trivedi, D.K.; Goodacre, R.; Fowler, S.J. Taking Your Breath Away: Metabolomics Breathes Life in to Personalized Medicine. Trends Biotechnol. 2014, 32, 538-548. [CrossRef] [PubMed]

7. Gaugg, M.T.; Engler, A.; Nussbaumer-Ochsner, Y.; Bregy, L.; Stöberl, A.S.; Gaisl, T.; Bruderer, T.; Zenobi, R.; Kohler, M.; MartinezLozano Sinues, P. Metabolic Effects of Inhaled Salbutamol Determined by Exhaled Breath Analysis. J. Breath Res. 2017, $11,46004$. [CrossRef] [PubMed]

8. Yan, Y.; Wang, Q.; Li, W.; Zhao, Z.; Yuan, X.; Huang, Y.; Duan, Y. Discovery of Potential Biomarkers in Exhaled Breath for Diagnosis of Type 2 Diabetes Mellitus Based on GC-MS with Metabolomics. RSC Adv. 2014, 4, 25430-25439. [CrossRef]

9. Jia, Z.; Patra, A.; Kutty, V.; Venkatesan, T. Critical Review of Volatile Organic Compound Analysis in Breath and In Vitro Cell Culture for Detection of Lung Cancer. Metabolites 2019, 9, 52. [CrossRef] [PubMed]

10. Tassopoulos, C.N.; Barnett, D.; Russell Fraser, T. Breath-Acetone and Blood-Sugar Measurements in Diabetes. Lancet 1969, 293, 1282-1286. [CrossRef]

11. Wang, Z.; Wang, C. Is Breath Acetone a Biomarker of Diabetes? A Historical Review on Breath Acetone Measurements. J. Breath Res. 2013, 7, 037109. [CrossRef]

12. Chien, P.-J.; Suzuki, T.; Tsujii, M.; Ye, M.; Minami, I.; Toda, K.; Otsuka, H.; Toma, K.; Arakawa, T.; Araki, K.; et al. Biochemical Gas Sensors (Biosniffers) Using Forward and Reverse Reactions of Secondary Alcohol Dehydrogenase for Breath Isopropanol and Acetone as Potential Volatile Biomarkers of Diabetes Mellitus. Anal. Chem. 2017, 89, 12261-12268. [CrossRef] [PubMed] 
13. Saasa, V.; Beukes, M.; Lemmer, Y.; Mwakikunga, B. Blood Ketone Bodies and Breath Acetone Analysis and Their Correlations in Type 2 Diabetes Mellitus. Diagnostics 2019, 9, 224. [CrossRef] [PubMed]

14. Ruzsányi, V.; Kalapos, M.P. Breath Acetone as a Potential Marker in Clinical Practice. J. Breath Res. 2017, 11, 24002. [CrossRef] [PubMed]

15. Mörk, A.K.; Johanson, G. A Human Physiological Model Describing Acetone Kinetics in Blood and Breath during Various Levels of Physical Exercise. Toxicol. Lett. 2006, 164, 6-15. [CrossRef] [PubMed]

16. Li, W.; Liu, Y.; Liu, Y.; Cheng, S.; Duan, Y. Exhaled Isopropanol: New Potential Biomarker in Diabetic Breathomics and Its Metabolic Correlations with Acetone. RSC Adv. 2017, 7, 17480-17488. [CrossRef]

17. Amiri, V.; Roshan, H.; Mirzaei, A.; Neri, G.; Ayesh, A.I. Nanostructured Metal Oxide-Based Acetone Gas Sensors: A Review. Sensors 2020, 20, 3096. [CrossRef]

18. Wiesenhofer, H.; Allers, M.; Zimmermann, S.; Güntner, A.T.; Pineau, N.J.; Lederer, W.; Agapiou, A.; Mayhew, C.A.; Ruzsanyi, V. Monitoring of Selected Skin- and Breath-Borne Volatile Organic Compounds Emitted from the Human Body Using Gas Chromatography Ion Mobility Spectrometry ( GC-IMS ). J. Chromatogr. B 2018, 1076, 29-34. [CrossRef]

19. Arasaradnam, R.P.; McFarlane, M.; Ling, K.; Wurie, S.; O'Connell, N.; Nwokolo, C.U.; Bardhan, K.D.; Skinner, J.; Savage, R.S.; Covington, J.A. Breathomics-Exhaled Volatile Organic Compound Analysis to Detect Hepatic Encephalopathy: A Pilot Study. J. Breath Res. 2016, 10, 016012. [CrossRef]

20. Shimouchi, A.; Nose, K.; Shirai, M. Analysis of Breath and Skin Gases Emanating During Exercise Using an Original Biogas Sampling System Connected to an Atmospheric Pressure Ionization Mass Spectrometer. IEEE Sens. J. 2010, 10, 85-91. [CrossRef]

21. Yamane, N.; Tsuda, T.; Nose, K.; Yamamoto, A.; Ishiguro, H.; Kondo, T. Relationship between Skin Acetone and Blood $\beta-$ Hydroxybutyrate Concentrations in Diabetes. Clin. Chim. Acta 2006, 365, 325-329. [CrossRef]

22. Sekine, Y.; Toyooka, S.; Watts, S.F. Determination of Acetaldehyde and Acetone Emanating from Human Skin Using a Passive Flux Sampler-HPLC System. J. Chromatogr. B Anal. Technol. Biomed. Life Sci. 2007, 859, 201-207. [CrossRef]

23. Mochalski, P.; King, J.; Unterkofler, K.; Hinterhuber, H.; Amann, A. Emission Rates of Selected Volatile Organic Compounds from Skin of Healthy Volunteers. J. Chromatogr. B Anal. Technol. Biomed. Life Sci. 2014, 959, 62-70. [CrossRef]

24. Fenske, J.D.; Paulson, S.E. Human Breath Emissions of VOCs. J. Air Waste Manag. Assoc. 1999, 49, 594-598. [CrossRef] [PubMed]

25. Arakawa, T.; Suzuki, T.; Tsujii, M.; Iitani, K.; Chien, P.J.; Ye, M.; Toma, K.; Iwasaki, Y.; Mitsubayashi, K. Real-Time Monitoring of Skin Ethanol Gas by a High-Sensitivity Gas Phase Biosensor (Bio-Sniffer) for the Non-Invasive Evaluation of Volatile Blood Compounds. Biosens. Bioelectron. 2019, 129, 245-253. [CrossRef] [PubMed]

26. Arakawa, T.; Aota, T.; Iitani, K.; Toma, K.; Iwasaki, Y.; Mitsubayashi, K. Skin Ethanol Gas Measurement System with a Biochemical Gas Sensor and Gas Concentrator toward Monitoring of Blood Volatile Compounds. Talanta 2020, 219, 121187. [CrossRef] [PubMed]

27. Lachenmeier, D.W. Safety Evaluation of Topical Applications of Ethanol on the Skin and inside the Oral Cavity. J. Occup. Med. Toxicol. 2008, 3, 1-16. [CrossRef] [PubMed]

28. Hair, M.E.; Gerkman, R.; Mathis, A.I.; Halámková, L.; Halámek, J. Noninvasive Concept for Optical Ethanol Sensing on the Skin Surface with Camera-Based Quantification. Anal. Chem. 2019, 91, 15860-15865. [CrossRef] [PubMed]

29. Giles, H.G.; Meggiorini, S.; Renaud, G.E.; Thiessen, J.J.; Vidins, E.I.; Compton, K.V.; Saldivia, V.; Orrego, H.; Israel, Y. Ethanol Vapor above Skin: Determination by a Gas Sensor Instrument and Relationship with Plasma Concentration. Alcohol. Clin. Exp. Res. 1987, 11, 249-253. [CrossRef] [PubMed]

30. Broza, Y.Y.; Zhou, X.; Yuan, M.; Qu, D.; Zheng, Y.; Vishinkin, R.; Khatib, M.; Wu, W.; Haick, H. Disease Detection with Molecular Biomarkers: From Chemistry of Body Fluids to Nature-Inspired Chemical Sensors. Chem. Rev. 2019, 119, 11761-11817. [CrossRef]

31. Saidi, T.; Zaim, O.; Moufid, M.; el Bari, N.; Ionescu, R.; Bouchikhi, B. Exhaled Breath Analysis Using Electronic Nose and Gas Chromatography-Mass Spectrometry for Non-Invasive Diagnosis of Chronic Kidney Disease, Diabetes Mellitus and Healthy Subjects. Sens. Actuators B Chem. 2018, 257, 178-188. [CrossRef]

32. le Maout, P.; Wojkiewicz, J.L.; Redon, N.; Lahuec, C.; Seguin, F.; Dupont, L.; Mikhaylov, S.; Noskov, Y.; Ogurtsov, N.; Pud, A. Polyaniline Nanocomposites Based Sensor Array for Breath Ammonia Analysis. Portable e-Nose Approach to Non-Invasive Diagnosis of Chronic Kidney Disease. Sens. Actuators B Chem. 2018, 274, 616-626. [CrossRef]

33. El Manouni el Hassani, S.; Berkhout, D.J.C.; Bosch, S.; Benninga, M.A.; de Boer, N.K.H.; de Meij, T.G.J. Application of Fecal Volatile Organic Compound Analysis in Clinical Practice: Current State and Future Perspectives. Chemosensors 2018, 6, 29. [CrossRef]

34. Kinoyama, M.; Nitta, H.; Watanabe, A.; Ueda, H. Acetone and Isoprene Concentrations in Exhaled Breath in Healthy Subjects. J. Health Sci. 2008, 54, 471-477. [CrossRef]

35. Huang, Z.; Liu, Y.; Mao, Y.; Chen, W.; Xiao, Z.; Yu, Y. Relationship between Glycated Haemoglobin Concentration and Erythrocyte Survival in Type 2 Diabetes Mellitus Determined by a Modified Carbon Monoxide Breath Test. J. Breath Res. 2018, $12,26004$. [CrossRef] [PubMed]

36. Mirzaei, A.; Kim, H.W.; Kim, S.S.; Neri, G. Nanostructured Semiconducting Metal Oxide Gas Sensors for Acetaldehyde Detection. Chemosensors 2019, 7, 56. [CrossRef]

37. Iitani, K.; Chien, P.J.; Suzuki, T.; Toma, K.; Arakawa, T.; Iwasaki, Y.; Mitsubayashi, K. Fiber-Optic Bio-Sniffer (Biochemical Gas Sensor) Using Reverse Reaction of Alcohol Dehydrogenase for Exhaled Acetaldehyde. ACS Sens. 2018, 3, 425-431. [CrossRef]

38. Das, S.; Pal, M. Review-Non-Invasive Monitoring of Human Health by Exhaled Breath Analysis: A Comprehensive Review. J. Electrochem. Soc. 2020, 167, 037562. [CrossRef] 
39. Usman, F.; Dennis, J.O.; Ahmed, A.Y.; Meriaudeau, F.; Ayodele, O.B.; Rabih, A.A.S. A Review of Biosensors for Non-Invasive Diabetes Monitoring and Screening in Human Exhaled Breath. IEEE Access 2019, 7, 5963-5974. [CrossRef]

40. Stefanuto, P.H.; Zanella, D.; Vercammen, J.; Henket, M.; Schleich, F.; Louis, R.; Focant, J.F. Multimodal Combination of GC $\times$ GC-HRTOFMS and SIFT-MS for Asthma Phenotyping Using Exhaled Breath. Sci. Rep. 2020, 10, 1-11. [CrossRef]

41. Ye, M.; Chien, P.J.; Toma, K.; Arakawa, T.; Mitsubayashi, K. An Acetone Bio-Sniffer (Gas Phase Biosensor) Enabling Assessment of Lipid Metabolism from Exhaled Breath. Biosens. Bioelectron. 2015, 73, 208-213. [CrossRef]

42. Arakawa, T.; Kita, K.; Wang, X.; Miyajima, K.; Toma, K.; Mitsubayashi, K. Chemiluminescent Imaging of Transpired Ethanol from the Palm for Evaluation of Alcohol Metabolism. Biosens. Bioelectron. 2015, 67, 570-575. [CrossRef]

43. Arakawa, T.; Sato, T.; Iitani, K.; Toma, K.; Mitsubayashi, K. Fluorometric Biosniffer Camera "Sniff-Cam" for Direct Imaging of Gaseous Ethanol in Breath and Transdermal Vapor. Anal. Chem. 2017, 89, 4495-4501. [CrossRef]

44. Iitani, K.; Toma, K.; Arakawa, T.; Mitsubayashi, K. Ultrasensitive Sniff-Cam for Biofluorometric-Imaging of Breath Ethanol Caused by Metabolism of Intestinal Flora. Anal. Chem. 2019, 91, 9458-9465. [CrossRef] [PubMed]

45. Iwasaki, Y.; Ishihara, K. Cell Membrane-Inspired Phospholipid Polymers for Developing Medical Devices with Excellent Biointerfaces. Sci. Technol. Adv. Mater. 2012, 13, 064101. [CrossRef] [PubMed]

46. Konvalina, G.; Haick, H. Sensors for Breath Testing: From Nanomaterials to Comprehensive Disease Detection. Acc. Chem. Res. 2014, 47, 66-76. [CrossRef] [PubMed] 